nature of the relationship just stated is remarkable. Since the above equations were found empirically from measurements, they must be assumed to represent only a first approximation to the exact relationship.

$$
\begin{gathered}
\text { Physical Institute, } \\
\text { University, } \\
\text { Lund. } \\
\text { Nov. } 4 .
\end{gathered}
$$

\section{Mechanism of Carbohydrate Oxidation}

Some new facts have been found suggesting that the first stage in the biological oxidation of carbohydrate is its conversion to glucose-6-phosphoric acid (or Robison ester), which is oxidized ${ }^{1}$ to 6-phosphogluconic acid. Dehydrogenation by a specific dehydrogenase co-enzyme system yields 6-phosphoketogluconic acid, probably the 2-keto acid, which is then decarboxylated. In animal tissues, where there is evidence ${ }^{2}$ that decarboxylation is oxidative, phospho-arabonic acid would result. Yeast carboxylase, which converts keto-acids to aldehydes, would yield arabinose phosphate, as recently suggested by Lipmann ${ }^{3}$. Further oxidation to the 3-carbon systems would then consist in a repetition of these reactions.

Respiration of brain slices (guinea pig, rat) is supported by addition of glucose and, to a lesser extent, of glucose monophosphate, but not by 6-phosphogluconic acid, gluconic acid or 2-ketogluconic acid. After destruction of the cells by grinding with sand, oxidation of glucose is no longer appreciable, but that of glucose-monophosphate, 6-phospho-gluconic acid, gluconic acid and 2-ketogluconic acid is clearly evident. These facts are explicable as follows: (1) the entry of glucose into the cell is accompanied by its phosphorylation; (2) in all the above substances, phosphorylation is the physiological mechanism of their activation; (3) primary oxidation products of carbohydrate are unable to penetrate the cell, whether phosphorylated or not.

Evidence that in yeast gluconic acid is attacked only when phosphorylated is provided by a study of the specific phosphohexonic dehydrogenase. The existence of this enzyme in Lebedew fluid, indicated by the work of Lipmann ${ }^{3}$, is proved by its isolation from this source by precipitation with acetate buffer

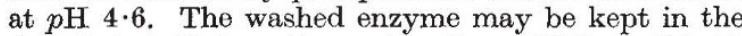
dry state. It is active only after addition of both Warburg oxidation co-enzyme $(0.01 \mathrm{mgm}$.$) and$ yellow enzyme, when the oxygen uptake with 6-phosphogluconic acid at $37 \cdot 5^{\circ}$ is theoretical for dehydrogenation to ketogluconic acid. A ketone fixative $(0.1 N$ hydrogen cyanide) is necessary, otherwise the reaction ceases after 30 minutes, as with animal lactic dehydrogenase ${ }^{4}$. Co-zymase, active in the lactic system, is inert; gluconic acid is not attacked whichever co-enzyme is used. Purified Warburg Zwischenferment contains little of this enzyme, which it closely resembles. Addition of carboxylase $e^{5}$ causes further oxidation and evolution of carbon dioxide equal to the oxygen uptake. Since this work was completed, a preliminary note by Warburg and Christian ${ }^{6}$ has appeared, in which they obtain further degradation of phosphohexonic acid by an apparently different enzyme preparation, hence the publication of this work in its present form.

Both dehydrogenase systems are insensitive to cyanide. In the ground-up brain $M / 500$ hydrogen cyanide inhibits reversibly 80 per cent of the oxygen uptake with hexose monophosphate or phosphohexonic acid as substrate. It is concluded that, in biological oxidation of carbohydrate by this system, indophenol oxidase and cytochrome participate. Theorell ${ }^{7}$ has shown that H-transport via yellow enzyme-cytochrome can occur. The above experiments suggest that this may be the actual mechanism of carbohydrate oxidation in vivo. As yet our attempts $^{B}$ to reconstruct the system from heart indophenol oxidase, cytochrome $c$, and the above enzymes, have resulted only in an inhibition of oxidation; other links, possibly cytochromes $a$ and $b$, may also be necessary. These experiments are being continued.

I am greatly indebted to Prof. O. Warburg for generous gifts of his enzyme and co-enzyme preparations.

Cancer Research Laboratory,

North of England Council,

British Empire Cancer Campaign,

Royal Victoria Infirmary,

Newcastle-upon-Tyne.

Nov. 26.

2 Warburg, Christian and Griese, Biochem. Z., 282, 157 (1935).

2 Weil-Malherbe, NATrRe, 138, 551 (1936); Chem. and Ind., 55, $838(1936)$.

${ }^{8}$ Lipmann, NATURE, 138, 588 (1936).

- Green and Brosteaux, Biochem. J., 30, 1489 (1936).

s Axmacher and Bergstermann, Biochem. Z., 272, 259 (1934).

- Warburg and Christian, Biochem. Z., 237, 440 (1936).

'Theorell, NATURE, 138, 687 (1936).

${ }^{8}$ Dickens and Weil-Malherbe (unpublished).

\section{Chemical Nature of Citrin}

IN a previous note (Rusznyák et al.) one of us reported on the isolation and physiological activity (vitamin nature) of the crystalline flavone fraction of lemon juice. The substance, being different from other known flavones, was termed 'citrin'.

Further work has shown citrin to consist of mixed crystals of two different dyes, one being hesperidine (m.p. $261^{\circ}$ ), the other an eriodictyol glucoside. Hesperidine forms the major part of citrin. The great reactivity and the colour reactions of citrin are due to the eriodictyol glucoside. Citrin contains no free eriodictyol. This substance can be isolated only after complete hydrolysis.

According to its formula, eriodictyol is but a demethylated hesperetine. This makes it probable that both glucosides constituting citrin are but two forms of the same flavanone glucoside. Eriodictyol glucoside was not found in any considerable quantity in unripe oranges, which, however, contain great quantities of hesperidine. This makes it probable that the eriodictyol glucoside is formed from hesperidine by demethylation on ripening of the fruit.

This research is being sponsored by the Josiah Macy Jr. Foundation, New York.

V. BRUCKNER. A. SZENT-GyörGYI.

Inst. Org. and Med. Chem., Szeged.

Nov. 21. 